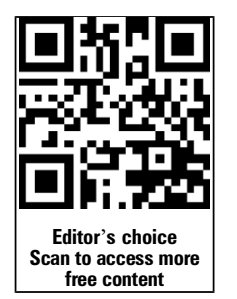

\title{
Cardiac resynchronisation therapy is not associated with a reduction in mortality or heart failure hospitalisation in patients with non-left bundle branch block QRS morphology: meta-analysis of randomised controlled trials
}

\author{
Colin Cunnington, ${ }^{1}$ Chun Shing Kwok, ${ }^{2}$ Duwarakan K Satchithananda, ${ }^{3}$ \\ Ashish Patwala, ${ }^{3}$ Muhammad A Khan, ${ }^{1}$ Amir Zaidi, ${ }^{1}$ Fozia Z Ahmed, ${ }^{1,2}$ \\ Mamas A Mamas $1,2,4$
}

\begin{abstract}
- Additional material is published online only. To view please visit the journal online (http://dx.doi.org/10.1136/ heartjnl-2014-306811).

${ }^{1}$ Manchester Heart Centre, Manchester Royal Infirmary, Manchester, UK

${ }^{2}$ Cardiovascular Institute, University of Manchester, Manchester, UK ${ }^{3}$ Department of Cardiology, University Hospital of North Staffordshire, Stoke-on-Trent, UK

${ }^{4}$ Farr Institute, University of Manchester, Manchester, UK
\end{abstract}

\section{Correspondence to}

Dr Colin Cunnington, Specialist Registrar in Cardiology, Manchester Royal Infirmary, Manchester M13 9WL, UK: colincunnington@aol.com

Received 12 September 2014 Revised 8 December 2014 Accepted 21 January 2015 Published Online First 12 February 2015

\section{SLinked}

http://dx.doi.org/10.1136/ heartjnl-2015-307553

\section{CrossMark}

To cite: Cunnington $C$ Kwok CS,

Satchithananda DK, et al. Heart 2015;101:

1456-1462

\section{ABSTRACT}

Objectives Recently published clinical guidelines recommend cardiac resynchronisation therapy (CRT) for patients with heart failure (HF) with reduced LVEF and non-left bundle branch block (non-LBBB) QRS morphology. We sought to define the potential benefit of CRT in these patients through meta-analysis of randomised controlled trials (RCTs) that have reported outcomes in patients with non-LBBB QRS morphology. Methods We searched MEDLINE and EMBASE for RCTs of CRT that reported outcomes according to QRS morphology. We performed meta-analysis of these RCTs to assess the effect of CRT on the end points of death, HF hospitalisation, and the composite of death and HF hospitalisation.

Results Five RCTs were analysed, including 6523 participants (1766 with non-LBBB QRS morphology). CRT was not associated with a reduction in death and/or HF hospitalisation in subjects with non-LBBB QRS morphology (HR $0.9995 \% \mathrm{Cl} 0.82$ to 1.20).

Conclusions CRT is not associated with a reduction in death or HF hospitalisation in patients with non-LBBB QRS morphology. Wide QRS with non-LBBB morphology remains an area of uncertainty for CRT, which is included in the recent European Society of Cardiology guidelines with a weaker strength of recommendation, but is not supported by a dedicated RCT.

\section{INTRODUCTION}

Several randomised controlled trials (RCTs), initially in patients with severe symptoms, ${ }^{1-3}$ and more recently in those with mild symptoms, ${ }^{4-6}$ have proven the efficacy of cardiac resynchronisation therapy (CRT) to reduce morbidity and mortality in patients with heart failure (HF) with LV systolic dysfunction and prolonged QRS duration. The benefit of CRT in patients with LVEF $<35 \%$ and left bundle branch block (LBBB) QRS morphology is well established, ${ }^{7}$ and this is reflected in the 2013 European Society of Cardiology (ESC) guidelines on cardiac pacing and CRT which give a strong recommendation (Class I) for CRT in patients with LBBB. ${ }^{8}$ However, a systematic review ${ }^{9}$ and meta-analysis ${ }^{7}$ of RCTs suggested a lack of benefit for CRT in patients with non-LBBB QRS morphology (ie, right bundle branch block (RBBB) or non-specific intraventricular conduction delay (NIVCD)). Furthermore, a recent retrospective analysis of over 24000 Medicare patients with a CRT defibrillator demonstrated worse outcomes in patients with non-LBBB QRS morphology compared with those with LBBB. ${ }^{10}$

The 2013 ESC guidelines give a Class IIa, Level B recommendation for CRT in patients with non-LBBB QRS morphology and QRS duration $>150 \mathrm{msec}$, and a weaker recommendation (Class IIb, Level B) for patients with non-LBBB QRS morphology with QRS duration 120-150 msec; both recommendations are for patients with LVEF $<35 \%$ and New York Heart Association (NYHA) class II-IV symptoms. ${ }^{8}$ Most recently, an updated technology appraisal of CRT and implantable cardioverter defibrillators (ICDs) published in the UK in June 2014 by the National Institute for Health and Care Excellence (NICE) continues to recommend CRT in patients with LVEF $<35 \%$ and non-LBBB QRS morphology with QRS duration $>150 \mathrm{msec}$ (all NYHA classes), as well as patients with QRS duration 120-149 msec with severe symptoms (NYHA class IV). ${ }^{11}$ Since the original meta-analysis, ${ }^{7}$ further CRT studies have been published in more contemporary cohorts. ${ }^{12-15}$ Given that the new recommendations from NICE have been made after publication of these analyses we sought to perform a contemporary meta-analysis of RCTs to assess the impact of CRT on death and HF hospitalisation in patients with non-LBBB QRS morphology.

\section{METHODS}

\section{Study eligibility}

Studies were considered for inclusion if they evaluated the use of CRT in participants with non-LBBB or RBBB QRS morphology and evaluated mortality or HF hospitalisation. Single arm studies, case reports, case series, letters and editorials were excluded but relevant reviews were retrieved to identify additional studies. 


\section{Search strategy}

Our search was carried out using the Ovid SP interface covering MEDLINE and EMBASE from inception until August 2014. The exact search terms were "cardiac resynchronization therapy" AND ("right bundle branch block" OR "non-left bundle branch block”).

Two reviewers (MAK and FZA) independently checked retrieved titles and abstracts for eligibility, and the relevant abstracts were checked by the other reviewers (CSK and MAM). Finally, two reviewers hand-searched bibliographies of included studies, as well as full-text review articles identified from the search (MAK and FZA).

\section{Data extraction}

Two reviewers (MAK and FZA) extracted data on study design, patient characteristics, treatment, follow-up, results and performed quality assessment of included studies. This was checked by the other reviewers (CSK and MAM).

\section{Data synthesis}

RevMan 5.1.6 (Nordic Cochrane Centre) was used to conduct random effects meta-analysis using inverse variance method for mean difference. The random effects model was used because it considers study heterogeneity when generating an average estimate. Statistical heterogeneity was evaluated through the $\mathrm{I}^{2}$ statistic with values of $30-60 \%$ representing moderate heterogeneity. ${ }^{16}$ We performed sensitivity analysis excluding studies that were RBBB only and performed additional meta-regression considering the effect of the start year of the trials, and another based on the mean year across the duration of the trials for analyses with more than two studies.

\section{Validity assessment}

Validity assessment was performed by considering use of blinding, outcome ascertainment, baseline differences, loss to follow-up and selective reporting. A subjective overall risk of bias was also assigned for each study based on these factors. In addition, we planned to conduct asymmetry testing for publication bias provided that there were $>10$ studies in the meta-analysis, and if statistical heterogeneity was $<50 \% .{ }^{17}$

\section{RESULTS}

\section{Study selection process}

Our search of MEDLINE and EMBASE yielded 337 results. After review of all titles and abstracts and full papers of relevant studies, five trials met the inclusion criteria: Cardiac ResynchronizationHeart Failure (CARE-HF), ${ }^{18}$ Comparison of Medical Therapy, Pacing and Defibrillation in Heart Failure (COMPANION), ${ }^{2}$ Resynchronization-Defibrillation for Ambulatory Heart Failure Trial (RAFT), ${ }^{4}{ }^{12}$ Multicentre Automatic Defibrillator Implantation Trial with Cardiac Resynchronization Therapy (MADIT-CRT), ${ }^{5} \quad 15 \quad 20$ and Resynchronization Reverses Remodelling in Systolic Left Ventricular Dysfunction (REVERSE). ${ }^{6}$ These results are shown in figure 1.

\section{Participant characteristics}

Five RCTs were included. These trials evaluated participants from USA, Canada, Europe, Turkey and Australia between January 2000 and September 2013. The sample size of these trials ranged from 610 participants to 1820 participants, and there was a total of 6523 participants of whom 1766 had non-LBBB. The mean age of participants across all five studies was 65 years and $75 \%$ of participants were male. These results are shown in table 1.

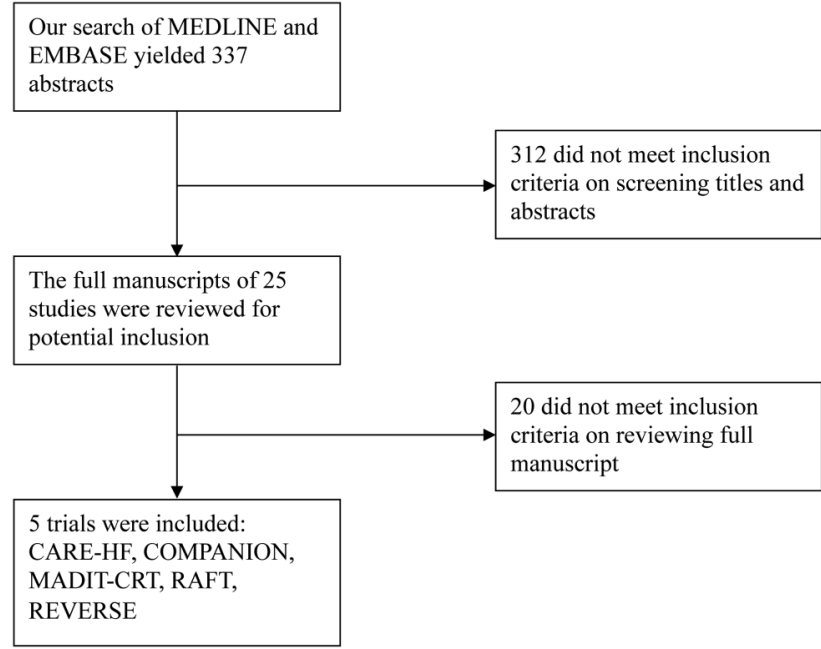

Figure 1 Study selection process.

Two of the five trials evaluated participants who had NHYA class III or IV symptoms (CARE-HF $\left.{ }^{1}, \mathrm{COMPANION}^{2}\right)$. Two trials evaluated NHYA class I or II (MADIT-CRT ${ }^{5}$, REVERSE $^{6}$ ) and one other trial evaluated participants with NHYA class II or III $\left(\right.$ RAFT $\left.^{4}\right)$. The LVEF inclusion criteria ranged from $\leq 30 \%$ to $\leq 40 \%$ and the minimum QRS duration was $\geq 120 \mathrm{msec}$. These results are shown in table 2 .

\section{Quality assessment of included studies}

The quality assessment of included trials is shown in online supplementary appendix 1 . All included trials had reliable measures for participant randomisation. Two of the included trials were non-blinded (CARE-HF ${ }^{1}, \mathrm{COMPANION}^{2}$ ) and for one other trial treating physicians were aware of study group assignments $\left(\right.$ MADIT-CRT $\left.^{5}\right)$. An adjudication or end points committee was used to ascertain outcome in four trials (MADIT-CRT $^{5}$, CARE-HF ${ }^{1}$, COMPANION $^{2}$, REVERSE $^{6}$ ). Three trials had no significant baseline differences between groups (MADIT-CRT ${ }^{5}$, COMPANION $^{2}$, RAFT $^{4}$ ).

\section{Risk of adverse outcomes with or without CRT in participants with non-LBBB QRS morphology}

All five trials were included in the evaluation of whether treatment with CRT affects adverse outcomes (death, HF hospitalisation, and the composite of death or HF hospitalisation) in participants with non-LBBB QRS morphology. Outcomes for patients without LBBB in each trial are shown in table 3. Two studies were pooled to evaluate the risk of death, which was not significant (RR 1.15 $95 \%$ CI 0.61 to $2.16, \mathrm{I}^{2}=75 \%$, two trials, 581 participants with non-LBBB) (MADIT-CRT ${ }^{20}$, RAFT $^{12}$ ). For risk of HF among the same two studies there was no evidence of any benefit associated with CRT treatment (RR $1.1195 \%$ CI 0.86 to $1.45, \mathrm{I}^{2}=0 \%$, two trials, 581 participants with non-LBBB). Considering death or HF, the pooled result of five studies was not significant (RR $0.9995 \%$ CI 0.82 to $1.20, \mathrm{I}^{2}=19 \%$, five trials, 1766 participants with non-LBBB) (CARE-HF ${ }^{18}$, COMPANION ${ }^{2}$, MADIT-CRT ${ }^{20}$, RAFT $^{12}$, REVERSE $\left.^{14}\right)$. These results are shown in figure 2 .

\section{Sensitivity analysis excluding trials of participants with RBBB}

Sensitivity analysis was performed excluding the CARE-HF ${ }^{1}$ trial that reported RBBB rather than non-LBBB. After exclusion 
Table 1 Study design, participants and inclusion criteria for patients with non-LBBB QRS morphology who did or did not receive CRT

\begin{tabular}{|c|c|c|c|c|c|c|c|}
\hline Study & Design & Date & Country & Sample size & Age & Sex & Participant inclusion criteria \\
\hline MADIT-CRT 51520 & $\begin{array}{l}\text { Randomised } \\
\text { controlled trial }\end{array}$ & $\begin{array}{l}\text { December } \\
2004 \text { to } \\
\text { September } \\
2013\end{array}$ & $\begin{array}{l}88 \text { centres in } \\
\text { USA, Canada } \\
\text { and Europe }\end{array}$ & $\begin{array}{l}1820 \text { total: } \\
1281 \text { LBBB, } \\
536 \text { non-LBBB, } \\
3 \text { unknown }\end{array}$ & $\begin{array}{l}\text { Total mean } \\
64 \text { years; } \\
\text { non-LBBB mean } \\
64 \text { years }\end{array}$ & $\begin{array}{l}\text { Total } 75 \% \\
\text { male; } \\
\text { non-LBBB } \\
90 \% \text { male }\end{array}$ & $\begin{array}{l}\text { Age }>21 \text { years with ischaemic (NYHA } \\
\text { I-II) or non-ischaemic (NYHA II) } \\
\text { cardiomyopathy, sinus rhythm, } \\
\text { QRS } \geq 130 \text { msec and LVEF } \leq 30 \%\end{array}$ \\
\hline CARE-HF ${ }^{118}$ & $\begin{array}{l}\text { Randomised } \\
\text { controlled trial }\end{array}$ & $\begin{array}{l}\text { January } 2001 \\
\text { to March } 2003\end{array}$ & $\begin{array}{l}82 \text { European } \\
\text { centres }\end{array}$ & $\begin{array}{l}775 \text { total: } \\
730 \text { LBBB, } \\
45 \text { non-LBBB }\end{array}$ & $\begin{array}{l}\text { Total mean } \\
67 \text { years }\end{array}$ & $\begin{array}{l}\text { Total } 73 \% \\
\text { male }\end{array}$ & $\begin{array}{l}\text { Age } \geq 18 \text { years with NHYA III-IV, LVEF } \\
\leq 35 \% \text {, height-adjusted LVEDD } \geq 30 \mathrm{~mm} \text {, } \\
\text { QRS } \geq 120 \text { msec and sinus rhythm } \\
\text { (additional dyssynchrony criteria required } \\
\text { for QRS } 120-149 \text { msec) }\end{array}$ \\
\hline COMPANION $^{2}$ & $\begin{array}{l}\text { Randomised } \\
\text { controlled trial }\end{array}$ & $\begin{array}{l}\text { January } 2000 \\
\text { to November } \\
2002\end{array}$ & 128 US centres & $\begin{array}{l}1520 \text { total: } \\
1075 \text { LBBB, } \\
444 \text { non-LBBB. }\end{array}$ & $\begin{array}{l}\text { Total mean } \\
67 \text { years }\end{array}$ & $\begin{array}{l}\text { Total } 67 \% \\
\text { male }\end{array}$ & $\begin{array}{l}\text { NHYA class III-IV ischaemic or } \\
\text { non-ischaemic cardiomyopathy, sinus } \\
\text { rhythm, QRS } \geq 120 \text { msec, LVEF } \leq 35 \% \\
\text { and HF hospitalisation within preceding } \\
12 \text { months }\end{array}$ \\
\hline RAFT $^{4} 12$ & $\begin{array}{l}\text { Randomised } \\
\text { controlled trial }\end{array}$ & $\begin{array}{l}\text { January } 2003 \\
\text { to February } \\
2009\end{array}$ & $\begin{array}{l}34 \text { centres in } \\
\text { Canada, Europe, } \\
\text { Turkey and } \\
\text { Australia }\end{array}$ & $\begin{array}{l}\text { Total 1798: } \\
1295 \text { LBBB, } \\
503 \text { non-LBBB }\end{array}$ & $\begin{array}{l}\text { Total mean } \\
66 \text { years }\end{array}$ & $\begin{array}{l}\text { Total } 83 \% \\
\text { male }\end{array}$ & $\begin{array}{l}\text { NYHA II-III ischaemic or non-ischaemic } \\
\text { cardiomyopathy, LVEF } \leq 30 \%, \text { QRS } \\
\text { duration } \geq 120 \text { msec (or paced QRS } \\
\geq 200 \mathrm{msec} \text { ) }\end{array}$ \\
\hline REVERSE $^{6} 14$ & $\begin{array}{l}\text { Randomised } \\
\text { controlled trial }\end{array}$ & $\begin{array}{l}\text { September } \\
2004 \text { to } \\
\text { September } \\
2006\end{array}$ & $\begin{array}{l}73 \text { centres in } \\
\text { USA, Canada } \\
\text { and Europe }\end{array}$ & $\begin{array}{l}\text { Total 610: } \\
369 \text { LBBB, } \\
238 \text { non-LBBB, } \\
3 \text { unknown }\end{array}$ & $\begin{array}{l}\text { Total } 63 \text { years; } \\
\text { non-LBBB } \\
63 \text { years }\end{array}$ & $\begin{array}{l}\text { Total } 79 \% \text {. } \\
\text { Non-LBBB } \\
88 \% \text { male }\end{array}$ & $\begin{array}{l}\text { NHYA I-II, sinus rhythm, QRS } \\
\geq 120 \mathrm{msec} \text {, LVEF } \leq 40 \%, \text { LVEDD } \\
\geq 55 \mathrm{~mm}\end{array}$ \\
\hline
\end{tabular}

6MWT, 6-min walk test; CRT, cardiac resynchronisation therapy; HF, heart failure; LBBB, left bundle branch block; LVEDD, left ventricular end-diastolic dimension; NYHA, New York Heart Association.

of this trial, the risk of death or HF was RR $1.0395 \%$ CI 0.83 to 1.27 (four trials).

\section{Meta-regression considering the effect of year of study}

We performed two sets of meta-regression analyses: one based on the start year of the trials, and the other based on the mean year across the duration of the trials for the analysis of death or HF (see online supplementary figure S1). The analysis based on the start year and mean year across the duration of the trials yielded similar findings. All relationships from both analyses were not statistically significant.

\section{DISCUSSION}

This meta-analysis of landmark CRT trials is the largest to date, including data from five RCTs and 6523 participants. We demonstrate no significant benefit of CRT in patients with non-LBBB QRS morphology, with an overall HR of 0.99 (95\% CI 0.82 to 1.20 ) for the composite of death and HF hospitalisation. Wide QRS with non-LBBB morphology remains an area of uncertainty for CRT, which is included in recent ESC guidelines with a weaker strength of recommendation, ${ }^{8}$ but is not supported by a dedicated RCT.
To date, there have been no RCTs to address the efficacy of CRT specifically in patients with non-LBBB QRS morphology. Subgroup analysis of all the individual RCTs of CRT has not shown any benefit in reducing death or HF hospitalisation in patients with non-LBBB QRS morphology. Small retrospective analyses that lack a non-CRT control arm have indicated worse outcomes in CRT recipients with non-LBBB compared with LBBB. ${ }^{21-24}$ However, in the absence of a dedicated RCT of CRT in non-LBBB, the most appropriate method to estimate the benefit of CRT in these patients is to perform meta-analysis of subgroup data from RCTs enrolling LBBB and non-LBBB subjects.

Our data confirm the findings of the previous meta-analysis of Sipahi $e t \mathrm{al}^{7}$ who demonstrated a similar lack of benefit of CRT in patients with non-LBBB QRS morphology. In addition to the RCTs analysed in the previous meta-analysis, the current study also includes data from the REVERSE ${ }^{6}$ trial, adding an additional 610 patients to the meta-analysis (283 patients without LBBB); this makes the current study the largest available meta-analysis of CRT in non-LBBB QRS morphology. Although the original report of REVERSE did not report death/HF outcomes according to QRS morphology, a subsequent

Table 2 Participant cardiac function and ECG findings for patients with non-LBBB QRS morphology who did or did not receive CRT

\begin{tabular}{|c|c|c|c|c|c|}
\hline Study & $\begin{array}{l}\text { NHYA } \\
\text { class }\end{array}$ & $\begin{array}{l}\text { LVEF } \\
(\%)\end{array}$ & Definitions of intraventricular conduction delays & $\begin{array}{l}\text { QRS } \\
\text { duration }\end{array}$ & $\begin{array}{l}\text { QRS } \\
\text { morphology }\end{array}$ \\
\hline MADIT-CRT 1520 & | or II & $\leq 30$ & LBBB, RBBB and NIVCD defined according to WHO criteria & $\geq 130 \mathrm{msec}$ & Non-LBBB \\
\hline CARE-HF ${ }^{1} 18$ & III or IV & $\leq 35$ & LBBB, RBBB and NIVCD classified according to 'standard classification' & $\geq 120 \mathrm{msec}$ & RBBB \\
\hline COMPANION $^{2}$ & III or IV & $\leq 35$ & Not stated & $\geq 120 \mathrm{msec}$ & Non-LBBB \\
\hline $\mathrm{RAFT}^{4} 12$ & II or III & $\leq 30$ & LBBB, RBBB and NIVCD defined according to AHA/ACC/HRS criteria & $\geq 120 \mathrm{msec}$ & Non-LBBB \\
\hline REVERSE $^{6} 14$ & | or II & $\leq 40$ & $\begin{array}{l}\text { LBBB defined according to WHO criteria; all other participants grouped under } \\
\text { non-LBBB }\end{array}$ & $\geq 120 \mathrm{msec}$ & Non-LBBB \\
\hline
\end{tabular}

ACC, American College of Cardiology; AHA, American Heart Association; CRT, cardiac resynchronisation therapy; HRS, Heart Rhythm Society; LBBB, left bundle branch block; NIVCD, non-specific intraventricular conduction delay; RBBB, right bundle branch block. 
Table 3 Treatment group and results for patients with non-LBBB QRS morphology who did or did not receive CRT

\begin{tabular}{|c|c|c|c|c|}
\hline Study & Intervention group & Control group & Follow-up & Outcomes \\
\hline MADIT-CRT 1520 & CRT-D and OMT & ICD and OMT & Median 5.6 years & $\begin{array}{l}\text { Death: } \\
\text { Non-LBBB: adjusted HR } 1.57 \text { (1.03-2.39), } p=0.04 \\
\text { HF event: } \\
\text { Non-LBBB: adjusted HR } 1.13(0.80-1.60), p=0.48 \\
\text { HF event or death: } \\
\text { Non-LBBB: adjusted HR } 1.27 \text { (0.94-1.73), } p<0.001\end{array}$ \\
\hline CARE-HF $^{1} 18$ & CRT-P and OMT & OMT alone & 29.4 months & $\begin{array}{l}\text { All-cause mortality or HF hospitalisation with baseline RBBB: } \\
\text { HR } 0.81(0.52-1.28) \text {. }\end{array}$ \\
\hline COMPANION $^{2}$ & OMT with CRT-P or CRT-D & OMT alone & 12 months & Composite events non-LBBB: $0.86(0.63-1.17), \mathrm{p}=0.34$. \\
\hline RAFT $^{4} 12$ & CRT-D & ICD alone & 40 months & $\begin{array}{l}\text { Cardiovascular mortality: } \\
\text { RBBB } 11(16.2 \%) \text { vs } 19(20.4 \%) \text {, HR } 0.83(0.39-1.74), \mathrm{p}=0.617 \\
\text { NIVCD } 19(17.9 \%) \text { vs } 20(19.8 \%), \text { HR } 0.81(0.43-1.51), \mathrm{p}=0.500 \\
\text { Calculated pooled non-LBBB: HR } 0.82(0.51-1.32) \\
\text { HF hospitalisation: } \\
\text { RBBB } 17(25.0 \%) \text { vs } 20(21.5 \%) \text {, HR } 1.24(0.65-2.36), \mathrm{p}=0.518 \\
\text { NIVCD } 32(30.2 \%) \text { vs } 29(28.7 \%), \text { HR } 1.00(0.60-1.66), \mathrm{p}=0.999 \\
\text { Calculated pooled non-LBBB: HR } 1.09(0.73-1.62) \\
\text { All-cause mortality or HF hospitalisation: } \\
\text { RBBB } 28(41.2 \%) \text { vs } 42(45.2 \%), \text { HR } 0.98(0.61-1.58), \mathrm{p}=0.930 \\
\text { NIVCD } 48(45.3 \%) \text { vs } 40(39.5 \%), \text { HR } 1.08(0.71-1.65), \mathrm{p}=0.790 \\
\text { Calculated pooled non-LBBB: HR } 1.03(0.75-1.42)\end{array}$ \\
\hline REVERSE $^{6} 14$ & CRT-D (CRT on) & CRT-D (CRT off) & 24 months & $\begin{array}{l}\text { Death or first HF hospitalisation: } \\
\text { RBBB: } 0.083(0.01-0.69) \\
\text { NIVCD: } 0.60(0.22-1.65) \\
\text { Calculated pooled non-LBBB: HR } 0.50(0.11-2.29) \text {. }\end{array}$ \\
\hline
\end{tabular}

CRT-D, cardiac resynchronisation therapy defibrillator; CRT-P, cardiac resynchronisation therapy pacemaker; HF, heart failure; ICD, implantable cardioverter-defibrillator; LBBB, left bundle branch block; OMT, optimal medical therapy; RBBB, right bundle branch block; NIVCD, non-specific intraventricular conduction delay.

retrospective analysis of QRS morphology yielded relevant subgroup data. ${ }^{14}$ The REVERSE analysis ${ }^{14}$ was not published at the time of the previous meta-analysis.

Two smaller studies, the Multicentre InSync Randomized Clinical Evaluation (MIRACLE) trial $^{3}{ }^{24}$ and the Multicentre InSync ICD Randomized Clinical Evaluation (MIRACLE ICD) trial $^{25}$ did not report death or HF hospitalisation endpoints according to QRS morphology, and so were not included in the present meta-analysis. However, these were the only RCTs to enrol patients with moderate-to-severe symptoms (NYHA class III-IV) and report symptom-driven end points (change in NYHA class or quality of life) according to QRS morphology. This is of particular relevance as the recent NICE technology appraisal recommends CRT in patients with non-LBBB QRS morphology with QRS duration 120-149 msec who have NYHA class IV symptoms. ${ }^{11}$ While symptomatic improvement was observed in the small cohort of subjects with non-LBBB QRS morphology, in MIRACLE, ${ }^{24}$ subjective reporting of symptoms is difficult to standardise and reproduce in comparison with objective measures such as death or HF hospitalisation. Furthermore, only 8 out of 78 non-LBBB participants in MIRACLE had NYHA class IV symptoms (the majority being NYHA class III). MIRACLE ICD demonstrated an improvement in NYHA class, quality of life and exercise capacity that was not significantly influenced by QRS morphology, although only a small number of patients with isolated RBBB were enrolled (25 in the CRT arm, 24 in the control arm), of whom only approximately 10\% were in NYHA class IV; the authors note that this post hoc analysis was not preplanned and may have been underpowered. $^{25}$

In addition to the meta-analysis by Sipahi et al, ${ }^{7}$ a further individual patient meta-analysis of five CRT trials was recently published by Cleland et al. ${ }^{13}$ Although this study showed no benefit of CRT on all-cause mortality, or the composite of death or HF hospitalisation, in univariate subgroup analyses of subjects with RBBB or NIVCD, when QRS duration was removed from multivariate analysis there was no interaction between QRS morphology and outcomes from CRT. ${ }^{13}$ Longer QRS duration is an important predictor of CRT response. ${ }^{26}$ It was observed that patients with NIVCD had shorter QRS duration compared with patients with LBBB and RBBB, which may account for the lack of benefit observed in patients without LBBB after multivariate analysis.

The study by Cleland et al examined a different set of RCTs compared with the present study, including data from the aforementioned MIRACLE and MIRACLE ICD trials, as well as CARE-HF, REVERSE and RAFT which were included in the current study. However, this analysis did not include data from COMPANION and MADIT-CRT, both large trials enrolling 1520 and 1820 patients, respectively, which were included in our data set. As such, the total sample size of our analysis is approximately double that of the analysis by Cleland et al (6523 vs 3872 patients), and the corresponding total number of patients with non-LBBB morphology is significantly greater in our study (1766 vs 813 patients).

Since the publication of the meta-analyses by Sipahi et $a l^{7}$ and Cleland et al, ${ }^{13}$ new data from the RAFT $^{12}$ and MADIT-CRT $^{15}$ trials have emerged. In RAFT, there was a benefit in patients without LBBB with NYHA class II-III symptoms after 2 years when QRS duration was $\geq 160 \mathrm{msec}$ (HR for death or HF hospitalisation $0.53,95 \%$ CI 0.29 to 0.96 ), but a trend towards possible harm in patients with QRS $<160 \mathrm{msec}$ (HR 1.38, 95\% CI 0.89 to 2.14 ). ${ }^{12}$ However, the largest single study of the effects of CRT in non-LBBB QRS morphology comes from a subgroup analysis of MADIT-CRT, which enrolled 536 non-LBBB participants with NYHA class I-II symptoms and demonstrated no significant reduction in the primary end point of death or HF hospitalisation in these patients. ${ }^{20}$ The recently 
Figure 2 Risk of adverse outcomes among patients with non-left bundle branch block (non-LBBB) QRS morphology who did or did not receive cardiac resynchronisation therapy (CRT).

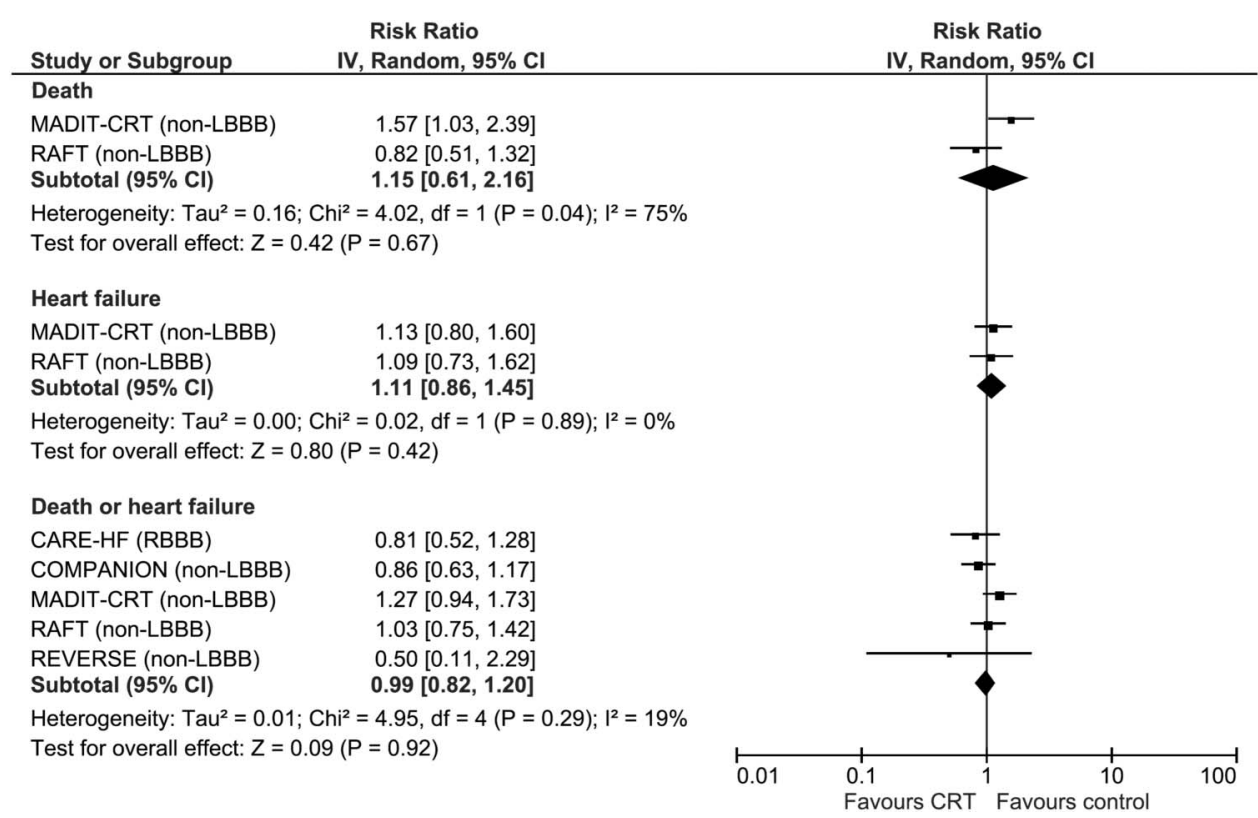

Risk Ratio

$1.57[1.03,2.39]$

$0.82[0.51,1.32]$
$1.15[0.61,2.16]$

$\begin{array}{ll}\text { RAFT (non-LBBB) } & 0.82[0.51,1.32] \\ \text { Subtotal }(\mathbf{9 5 \%} \mathrm{Cl}) & \mathbf{1 . 1 5}[0.61, \mathbf{2 . 1 6}]\end{array}$

Heterogeneity: $\mathrm{Tau}^{2}=0.16 ; \mathrm{Chi}^{2}=4.02, \mathrm{df}=1(\mathrm{P}=0.04) ; \mathrm{I}^{2}=75 \%$

Test for overall effect: $Z=0.42(P=0.67)$

Heart failure

MADIT-CRT (non-LBBB)

$80,1.60$

$1.09[0.73,1.62]$

Heterogeneity: $\mathrm{Tau}^{2}=0.00 ; \mathrm{Chi}^{2}=0.02, \mathrm{df}=1(\mathrm{P}=0.89) ; \mathrm{I}^{2}=0 \%$

Test for overall effect: $Z=0.80(P=0.42$

Death or heart failure

CARE-HF (RBBB)

COMPANION (non-LBBB)

$0.81[0.52,1.28]$

$0.86[0.63,1.17]$

$27[0.94,1.73]$

$0.99[0.82,1.20]$

Heterogeneity: $\mathrm{Tau}^{2}=0.01 ; \mathrm{Chi}^{2}=4.95, \mathrm{df}=4(\mathrm{P}=0.29) ; \mathrm{I}^{2}=19 \%$ published 7-year follow-up data from MADIT-CRT confirmed no clinical benefit of CRT in patients without LBBB for several end points, and non-LBBB was independently associated with an increase in mortality (HR $1.57,95 \%$ CI 1.03 to 2.39 ) following adjustment for baseline covariates including QRS duration. ${ }^{15}$

Differences in cardiac physiology between LBBB and non-LBBB QRS morphology likely underpin the lack of benefit of CRT observed in the latter group. In LBBB RV contraction occurs first, and LV contraction is dyssynchronous due to initial contraction of the septum against the non-activated LV free wall. The main aim of CRT is to ameliorate this mechanical dyssynchrony. Several studies have investigated ventricular electrical activation patterns in patients with wide QRS. ${ }^{27-31}$ Initial work indicated that LV activation delay may be similar between HF patients with $\mathrm{RBBB}$ and $\mathrm{LBBB}^{30}$ however this study only included six patients with RBBB. More recently it has been shown that there is significant heterogeneity in LV activation time (LVAT) among patients with HF with RBBB, with over $50 \%$ of RBBB subjects having LVAT $\leq 100 \mathrm{msec}$, similar to patients with HF with narrow QRS, ${ }^{27}$ in whom CRT has been shown to be of no benefit (or possibly harmful) in the large Echocardiography Guided Cardiac Resynchronisation Therapy (EchoCRT) RCT; ${ }^{32}$ in contrast patients with LBBB had significantly longer LVAT, despite similar QRS duration to patients with RBBB. Importantly, a small number of patients with RBBB had prolonged LVAT, similar to that seen in patients with LBBB. $^{27}$ These findings may provide a potential explanation for the apparent heterogeneity of CRT response observed in patients without LBBB in the RAFT analysis. ${ }^{12}$ Work published very recently has also demonstrated significantly shorter LVAT and greater heterogeneity in LV activation pattern in patients with NIVCD compared with LBBB. ${ }^{28}$ The same study has suggested that ventricular electrical uncoupling (the difference between LV and RV activation times) may be a more powerful predictor of CRT response than QRS duration or the presence of LBBB. ${ }^{28}$ Furthermore, it has also been shown that there may be significant heterogeneity in ventricular activation patterns even within cohorts of patients with LBBB. ${ }^{29} 31$

These electrocardiographic activation mapping studies serve to illustrate the highly complex relationship between QRS morphology and QRS duration. Furthermore, other important clinical variables such as gender may influence this relationship, with women deriving greater prognostic benefit from CRT than men in MADIT-CRT; notably in this trial a greater proportion of women had LBBB compared with men $(87 \%$ and $65 \%$, respectively). ${ }^{33}$ More recently, women have been shown to derive potential benefit from CRT at narrower QRS durations than men. ${ }^{34}$ Although a previous meta-analysis showed that QRS duration $\leq 150$ msec was not associated with improvements in clinical outcome following CRT, ${ }^{26}$ recent work, including the individual patient meta-analysis by Cleland et al, ${ }^{13}$ suggests that there is a continuous relationship between QRS duration and magnitude of CRT response, particularly in patients with LBBB. $^{12} 34$ Furthermore, the Cleland meta-analysis suggested possible mortality benefit with QRS $\geq 126 \mathrm{msec}$, with robust evidence for benefit with QRS $\geq 140$ msec. $^{13}$ Accordingly, the authors' data provides support to the current NICE and ESC recommendations for CRT in patients with LBBB with QRS $\geq 120 \mathrm{msec}$, despite the findings of the previous meta-analysis, ${ }^{26}$ as the cut-off of QRS $\geq 150 \mathrm{msec}$ represents an arbitrary figure used to dichotomise RCTs for subgroup analysis.

In contrast, we do not feel that differences in bundle branch block morphology can be considered as arbitrary cut-offs to be used in the same way that the QRS duration $\geq 150 \mathrm{msec}$ value has been used, as the electrocardiographic activation mapping studies support the hypothesis that LBBB, RBBB and NIVCD represent different pathophysiological entities and thus different substrates for CRT therapy. Thus, in contrast to QRS duration, there is not likely to be a continuous relationship between QRS morphologies and CRT response. Accordingly, the data from our meta-analysis does not support the use of CRT in patients with non-LBBB QRS morphology, regardless of QRS duration.

\section{Strengths and limitations}

The major strength of this meta-analysis is the large number of patients included in the analysis, making it the largest analysis to date of CRT in non-LBBB QRS morphology. The main limitation is the use of subgroup data for the meta-analysis, rather than individual patient data, and therefore our data has limited utility in assessing the interaction of QRS morphology with other important clinical variables, for example, QRS duration. 


\section{Key messages}

What is already known on this subject? Cardiac resynchronisation therapy (CRT) is recommended for patients with severe LV systolic dysfunction and QRS duration $\geq 120 \mathrm{msec}$.

Previous analyses have suggested a lack of benefit in patients with non-left bundle branch block (LBBB) QRS morphology.

What might this study add?

This is the largest CRT meta-analysis to date.

CRT is not associated with a reduction in death or heart failure hospitalisation in patients with non-LBBB QRS morphology.

How might this impact on clinical practice?

Clinicians need to reconsider the risk versus benefit of CRT in patients with non-LBBB QRS morphology as recommended in contemporary CRT guidelines.

In the absence of a dedicated non-LBBB RCT, an individual patient-level analysis of CRT efficacy according to QRS duration in these subjects is mandated. It is also noteworthy that there is a significant time span (13 years) across the enrolment period of the included trials, and as such the possibility of heterogeneity due to advances in other HF therapies cannot be excluded through meta-regression without access to individual patientlevel data. Furthermore, our analysis only included mortality and HF hospitalisation as end points, and not symptom-driven end points such as quality of life or change in NYHA class; as such we cannot exclude a symptomatic benefit of CRT in patients without LBBB, although data on these outcomes in patients without LBBB is even more limited.

\section{CONCLUSION}

This meta-analysis shows no reduction in death or HF hospitalisation from CRT in patients with non-LBBB QRS morphology. Wide QRS with non-LBBB morphology remains an area of uncertainty for implanting a CRT device, included in recent ESC guidelines with a weaker strength of the recommendation, but not supported by a dedicated trial. A dedicated RCT of CRT in patients with non-LBBB QRS morphology is needed to establish the efficacy of CRT in this subset of patients with HF.

Correction notice The CRT outcomes for the RBBB subgroup in the CARE-HF and MIRACLE trials had been erroneous in the original published version of the manuscript; these data have now been amended with the correct figures. Importantly, after these errors have been addressed, the principal findings of the analysis are unchanged, in that CRT is not associated with reduction in mortality or heart failure hospitalisation in patients with non-LBBB QRS morphology.

Contributors CC and CSK drafted the manuscript. MAK and FZA performed data extraction. CSK performed the literature search and meta-analysis. MAM and CSK checked the results of the data extraction. MAM, DKS, AP and AZ critically reviewed the manuscript.

Competing interests None.

Provenance and peer review Not commissioned; externally peer reviewed.

\section{REFERENCES}

1 Cleland JG, Daubert JC, Erdmann E, et al. The effect of cardiac resynchronization on morbidity and mortality in heart failure. N Engl J Med 2005;352:1539-49.

2 Bristow MR, Saxon LA, Boehmer J, et al. Cardiac-resynchronization therapy with or without an implantable defibrillator in advanced chronic heart failure. N Engl J Med 2004;350:2140-50.

3 Abraham WT, Fisher WG, Smith AL, et al. Cardiac resynchronization in chronic heart failure. N Engl J Med 2002;346:1845-53.
4 Tang AS, Wells GA, Talajic M, et al. Cardiac-resynchronization therapy for mild-to-moderate heart failure. N Engl J Med 2010;363:2385-95.

5 Moss AJ, Hall WJ, Cannom DS, et al. Cardiac-resynchronization therapy for the prevention of heart-failure events. N Engl J Med 2009;361:1329-38.

6 Linde C, Abraham WT, Gold MR, et al. Randomized trial of cardiac resynchronization in mildly symptomatic heart failure patients and in asymptomatic patients with left ventricular dysfunction and previous heart failure symptoms. J Am Coll Cardiol 2008;52:1834-43.

7 Sipahi I, Chou JC, Hyden M, et al. Effect of QRS morphology on clinical event reduction with cardiac resynchronization therapy: meta-analysis of randomized controlled trials. Am Heart J 2012;163:260-7 e3.

8 Brignole M, Auricchio A, Baron-Esquivias G, et al. 2013 ESC Guidelines on cardiac pacing and cardiac resynchronization therapy: the Task Force on cardiac pacing and resynchronization therapy of the European Society of Cardiology (ESC). Developed in collaboration with the European Heart Rhythm Association (EHRA). Eur Heart J 2013;34:2281-329.

9 Nery PB, Ha AC, Keren A, et al. Cardiac resynchronization therapy in patients with left ventricular systolic dysfunction and right bundle branch block: a systematic review. Heart Rhythm 2011;8:1083-7.

10 Peterson PN, Greiner MA, Qualls LG, et al. QRS duration, bundle-branch block morphology, and outcomes among older patients with heart failure receiving cardiac resynchronization therapy. JAMA 2013;310:617-26.

11 National Institute for Health and Care Excellence. Implantable cardioverter defibrillators and cardiac resynchronisation therapy for arrhythmias and heart failure (review of TA95 and TA120) 2014. http://www.nice.org.uk/guidance/ta314/ resources/guidance-implantable-cardioverter-defibrillators-and-cardiacresynchronisation-therapy-for-arrhythmias-and-heart-failure-review-of-ta95-andta120-pdf

12 Birnie DH, Ha A, Higginson L, et al. Impact of QRS morphology and duration on outcomes after cardiac resynchronization therapy: Results from the Resynchronization-Defibrillation for Ambulatory Heart Failure Trial (RAFT). Circ Heart Fail 2013;6:1190-8.

13 Cleland JG, Abraham WT, Linde C, et al. An individual patient meta-analysis of five randomized trials assessing the effects of cardiac resynchronization therapy on morbidity and mortality in patients with symptomatic heart failure. Eur Heart $J$ 2013;34:3547-56.

14 Gold MR, Thebault C, Linde C, et al. Effect of QRS duration and morphology on cardiac resynchronization therapy outcomes in mild heart failure: results from the Resynchronization Reverses Remodeling in Systolic Left Ventricular Dysfunction (REVERSE) study. Circulation 2012;126:822-9.

15 Goldenberg I, Kutyifa V, Klein HU, et al. Survival with cardiac-resynchronization therapy in mild heart failure. N Engl J Med 2014;370:1694-701.

16 Higgins JPT, Deeks JJ, Altman DG. Chapter 9: analysing data and undertaking meta-analyses. In: Higgins JPT, Green S. eds. Cochrane handbook for systematic reviews of interventions. Chichester, UK: John Wiley \& Sons, 2008.

17 Ioannidis JP, Trikalinos TA. The appropriateness of asymmetry tests for publication bias in meta-analyses: a large survey. CMAJ 2007;176:1091-6.

18 Gervais R, Leclercq C, Shankar A, et al. Surface electrocardiogram to predict outcome in candidates for cardiac resynchronization therapy: a sub-analysis of the CARE-HF trial. Eur J Heart Fail 2009;11:699-705.

19 Aranda JM Jr, Conti JB, Johnson JW, et al. Cardiac resynchronization therapy in patients with heart failure and conduction abnormalities other than left bundlebranch block: analysis of the Multicenter InSync Randomized Clinical Evaluation (MIRACLE). Clin Cardiol 2004;27:678-82.

20 Zareba W, Klein H, Cygankiewicz I, et al. Effectiveness of cardiac resynchronization therapy by QRS morphology in the Multicenter Automatic Defibrillator Implantation Trial-Cardiac Resynchronization Therapy (MADIT-CRT). Circulation 2011;123:1061-72.

21 Rickard J, Kumbhani DJ, Gorodeski EZ, et al. Cardiac resynchronization therapy in non-left bundle branch block morphologies. Pacing Clin Electrophysiol 2010;33:590-5.

22 Wokhlu A, Rea RF, Asirvatham SJ, et al. Upgrade and de novo cardiac resynchronization therapy: impact of paced or intrinsic QRS morphology on outcomes and survival. Heart Rhythm 2009;6:1439-47.

23 Adelstein EC, Saba S. Usefulness of baseline electrocardiographic QRS complex pattern to predict response to cardiac resynchronization. Am J Cardiol 2009; 103:238-42.

24 Egoavil CA, Ho RT, Greenspon AJ, et al. Cardiac resynchronization therapy in patients with right bundle branch block: analysis of pooled data from the MIRACLE and Contak CD trials. Heart Rhythm 2005;2:611-5.

25 Young JB, Abraham WT, Smith AL, et al. Combined cardiac resynchronization and implantable cardioversion defibrillation in advanced chronic heart failure: the MIRACLE ICD Trial. JAMA 2003;289:2685-94.

26 Sipahi I, Carrigan TP, Rowland DY, et al. Impact of QRS duration on clinical event reduction with cardiac resynchronization therapy: meta-analysis of randomized controlled trials. Arch Intern Med 2011;171:1454-62.

27 Varma N. Left ventricular conduction delays and relation to QRS configuration in patients with left ventricular dysfunction. Am J Cardiol 2009;103:1578-85. 
28 Ploux S, Lumens J, Whinnett Z, et al. Noninvasive electrocardiographic mapping to improve patient selection for cardiac resynchronization therapy: beyond QRS duration and left bundle branch block morphology. J Am Coll Cardiol 2013;61: 2435-43.

29 Auricchio A, Fantoni C, Regoli F, et al. Characterization of left ventricular activation in patients with heart failure and left bundle-branch block. Circulation 2004;109:1133-9.

30 Fantoni C, Kawabata M, Massaro R, et al. Right and left ventricular activation sequence in patients with heart failure and right bundle branch block: a detailed analysis using three-dimensional non-fluoroscopic electroanatomic mapping system. J Cardiovasc Electrophysiol 2005;16:112-9.
31 Vassallo JA, Cassidy DM, Marchlinski FE, et al. Endocardial activation of left bundle branch block. Circulation 1984;69:914-23.

32 Ruschitzka F, Abraham WT, Singh JP, et al. Cardiac-resynchronization therapy in heart failure with a narrow QRS complex. N Engl J Med 2013;369:1395-405.

33 Arshad A, Moss AJ, Foster E, et al. Cardiac resynchronization therapy is more effective in women than in men: the MADIT-CRT (Multicenter Automatic Defibrillator Implantation Trial with Cardiac Resynchronization Therapy) trial. J Am Coll Cardiol 2011;57:813-20

34 Varma N, Manne M, Nguyen D, et al. Probability and magnitude of response to cardiac resynchronization therapy according to QRS duration and gender in nonischemic cardiomyopathy and LBBB. Heart Rhythm 2014;11:1139-47. 